\title{
İş sağlığı ve güvenliği öğrencilerinin kardiyopulmoner resüsitasyon becerisi
}

\author{
Cardiopulmonary resuscitation skill levels of the occupational health and safety students
}

Atakan Yılmaz, Murat Seyit, Ramazan Sabırlı, Mert Özen

Gönderilme tarihi:28.09.2018

Kabul tarihi:09.11.2018

\section{Özet}

Amaç: Kardiyak arrest durumlarında yaşama tutunma şansı erken kardiyopulmoner resüsitasyon (KPR)'a bağlıdır. Çalışmamızın amacı, geleceğin iş sağlığı ve güvenliği uzmanları olacak öğrencilerin ani kardiyak arrest geliştiği durumlarda 112 acil yardım ambulans ekipleri olay yerine ulaşmadan temel yaşam desteği (TYD)'ne hemen başlayabilme özgüvenlerini ve bu konu ile ilgili bilgi ve beceri düzeylerini belirlemektir.

Gereç ve yöntem: Çalışmamıza Pamukkale Üniversitesi iş sağlığı ve güvenliği bölümü 2014-2015 ve 20152016 öğretim yılında 1. sınıfta öğrenim gören 254 öğrenci alınmıştır. Öğrencilerin cinsiyet, ehliyet sahibi olup olmama, sporla ilgilenme, üniversite öncesinde sözel veya maket üzerinde KPR eğitimi alma, üniversitede sözel veya maket üzerinde KPR eğitimi almış olmasının bası yeri, bası derinliği, bası hızı, bası ritmi puanlarına etkisi ve eğitim öncesi-sonrasında KPR yapabilme özgüvenleri araştııılmıştır.

Bulgular: Öğrencilerin 209'u (\%82,3) erkek, 45’i (\%17,7) kadındı. Çalışmada eğitim öncesi ve sonrasında sorulan "Şu an KPR yapar mısın?" sorusuna verilen cevaplardan yola çıkıldığında kişilerin öz güvenlerinde anlamlı fark bulundu ( $p=0,0001)$. Üniversite öncesinde KPR konusunda maket üzerinde eğitim alan ve almayan öğrenciler arasında bası derinliği puanı açısından istatistiksel anlamlı fark saptandı $(p=0,047)$.

Çalışma öncesinde üniversitede sözel olarak KPR eğitimi alan ve almayan öğrencilerin bası derinliği puanı açısından istatistiksel anlamlı fark saptandı $(p=0,037)$. Üniversitede maket üzerinde KPR eğitimi alan ve almayan öğrencilerin bası yeri, bası derinliği ve ritm açısından iki grup arasında anlamlı fark mevcut olduğu saptandı ( $p$ değerleri sırasıyla; $p=0,028, p=0,022, p=0,025$ ).

Sonuç: Yaşadıkları ve çalıştıkları bölgelerde çoğu zaman olay yerine sağlık profesyonellerinden daha hızlı ulaşabilecek olan iş sağlığı güvenliği öğrencilerine TYD eğitimleri öğrenim hayatlarının ilk yıllarından başlayarak özellikle maket üzerinde verilmeli, bilgi ve becerileri artırılması sağlanmalıdır.

Anahtar Kelimeler: Temel yaşam desteği, TYD, iş sağlığı ve güvenliği öğrencileri, kardiyopulmoner resüsitasyon, KPR.

Yılmaz A, Seyit M, Sabırlı R, Özen $M$. İş sağlığı ve güvenliği öğrencilerinin kardiyopulmoner resüsitasyon becerisi. Pam Tıp Derg 2019;12:101-106.

\footnotetext{
Abstract

Purpose: Chances of survival in cardiac arrest depend on early cardiopulmonary resuscitation (CPR). The purpose of our study is to determine the level of knowledge and skills of the occupational health and safety students, who are medical candidates for the future, about the subject and the self-confidence of initiating basic life support (BLS) immediately without the 112 emergency aid ambulance crew arriving at the scene in case of a sudden cardiac arrest.

Materials and methods: The participants include 289 freshmen students studying at the faculty of occupational health and safety, Pamukkale University, Denizli, Turkey during the 2014-2015 and 2015-2016 academic year. The effects of gender, driving license, sporting interest, receiving word attack skills education and having cardiopulmonary resuscitation (CPR) training on the model before university, receiving word attack skills education and having CPR training on the model at university upon the location of press, depth of press, speed of press, and pressure rhythm scores were investigated.

Results: 209 students (82.3\%) were male and 45 students (17.7\%) were female. There is a significant difference in the self-confidence of the students in the study before and after the education, the answers given to the question "Do you currently have CPR training?" ( $p=0.0001)$. A statistically significant difference was found in terms of pressure depth score among students who had no education on the model of CPR before and after the university $(p=0.047)$. A significant difference was found in terms of pressure depth score of students who received or did not receive CPR training verbally at the university before the study $(p=0.037)$. A significant

Atakan Yılmaz, Dr. Öğr. Üyesi, Pamukkale Üniversitesi, Tıp Fakültesi, Acil Tıp ABD, DENIZLI, e-posta:dr_atakanyilmaz@yahoo.com (orcid. org/0000-0002-9773-5681) (Sorumlu yazar)

Murat Seyit, Dr. Öğr. Üyesi, Pamukkale Üniversitesi, Tıp Fakültesi, Acil Tıp ABD, DENIZLI, e-posta:muratseyit@yahoo.com (orcid.org/00000002-8324-9471)

Ramazan Sabırlı, Uzm. Dr. Servergazi Devlet Hastanesi, Acil Servis, DENIZLI, e-posta:ramazan_sabirli@hotmail.com (orcid.org/0000-00034599-5833)

Mert Özen, Dr. Öğr. Üyesi, Pamukkale Üniversitesi, Tıp Fakültesi, Acil Tıp ABD, DENIZLI, e-posta:ozenmert@yahoo.com (orcid.org/0000-00016653-3756)
} 
difference was found between the two groups in terms of pressure place, pressure depth, and rhythm of the students who received and did not receive CPR on the model $(p=0.028, p=0.022, p=0.025$, respectively).

Conclusion: As a result, occupational health and safety students who are often capable of reaching the scene faster than the health care professionals in the regions where they live should be provided with BLS trainings down from the start of their education life in an attempt to increase their knowledge and skills.

Key Words: Basic life support, BLS, occupational health and safety students, cardiopulmonary resusciation, CPR.

Yılmaz A, Seyit M, Sabırlı R, Özen M. Cardiopulmonary resuscitation skill levels of the occupational health and safety students. Pam Med J 2019;12:101-106.

\section{Giriş}

Kardiyopulmoner resüsitasyon (KPR), hangi sebebe bağlı olursa olsun solunum ve dolaşımı durmuş hastanın, hava yolu açıklığının sağlanması ve solunum ile dolaşım sisteminin desteklenmesi olarak tanımlanır. Kardiyopulmoner resüsitasyon üç aşamada gerçekleştirilir; temel yaşam desteği (TYD), ileri yaşam desteği (IYD), uzun vadeli yaşam desteği.

Etkili ilk kalp masajı uygulaması olarak da 1812 yılında, suda boğulan kişiyi at üzerine koyarak, atın koşması sağlanarak hasta yaşama döndürülmeye çalışılmıştır [1]. Kapalı kalp masajı, ilk olarak 1960 yılında tanımlanmıştır. $\mathrm{Bu}$ dönemde Kouwenhoven kardiyak masajı ve yapay solunumu başarıyla uygulamıştır. Kardiyak masaj yapılmadığı takdirde anoksi nedeniyle hayati organlarda geri dönüşümsüz hasarlar meydana gelebileceği söylenmiştir [2]. Ağızdan ağıza solunum ile kapalı göğüs kompresyonunun kombine kullanılmasıyla yapılan kurtarma işlemleri Safar tarafından 1963'de ilk kez KPR olarak adlandırılmıştır [3]. Başta Amerikan Kalp Birliği (AHA) olmak üzere 1986 yılında gerçekleştirilen konferanstan sonra, 1992'de 5. Ulusal Konferansında KPR konusu yeniden ele alınmış ve bir konsensus oluşturulmuştur [4].

Son derece kritik olan bu durumda müdahalenin en iyi şekilde yapılması, bütün bilimsel yöntemlerin gereken zamanda, gereken sırada ve gereken biçimde uygulanması; uygulamada hiçbir eksiklik veya hatanın olmaması son derece önemlidir [5]. Yapılan çalışmalarda TYD uygulamalarında yetersizlikler bildirilmiştir [6]. Hastane dışı kardiyak arrestlerde erken girişim, kritik durumlardaki hastaların sağ kalım oranlarını olumlu yönde etkiler [7, 8]. Yapılan bir çalışmada olay yerinde TYD uygulanan hastaların sağ kalım oranları $\% 2,8$ iken, uygulanmayanlarda bu oranın \%1'e gerilediği görülmüştür [9]. Erken KPR sağ kalımı artırmasına rağmen genellikle sağlık profesyonelleri gelene kadar KPR'ye başlanmamaktadır [10]. TYD eğitimleri ile halktan kurtarıcıların sayıları artırılarak arrestin hayata tutunma şansı artırılabilir [11].

Çalışmamızın amacı ise, geleceğin iş sağlığı ve güvenliği uzmanları olacak öğrencilerin ani kardiyak arrest geliştiği durumlarda 112 acil yardım ambulans ekipleri olay yerine ulaşmadan TYD'ne hemen başlayabilme özgüvenlerini ve bu konu ile ilgili bilgi ve beceri düzeylerini belirlemektir.

\section{Gereç ve yöntem}

$\mathrm{Bu}$ çalışma için Pamukkale Üniversitesi girişimsel olmayan klinik araştırmalar etik kurulu 08.05.2018 tarih ve 09 sayı ile 60116787020/33325 sayılı kurul kararı ile onay alınmıştır. Pamukkale Üniversitesi 2014-2015 ve 20152016 öğretim yıllarındaki iş sağlığı ve güvenliği birinci sınıf öğrencilerine yaptığımız Temel Yaşam Desteği uygulamalarındaki veriler kullanılarak çalışma yapılmıştır. 2014-2015 eğitim döneminde 2 sınıfa, 2015-2016 eğitim döneminde 2 sınıf olmak üzere toplamda 4 sınıfa TYD eğitimi verildi. Eğitim verilen öğrencilerden çalışmaya katılmak istemeyen olmadı. Eğitim sonrası her öğrencinin maket üzerinde KPR uygulaması istenmiştir. Eğitimin verildiği yılda kullanılan AHA kılavuzundaki istenen kriterlere göre öğrencilerin KPR uygulama becerileri değerlendirildi. Değerlendirme sonuçları anket formuna kaydedildi. Eğitim sonrası maket üzerinde uygulama yaptıkları zaman elde edilen veriler istatistiksel analize alındı.

Öğrencilerin öğrenim durumu, cinsiyet, boy, kilo, doğum yeri, okuduğu lise, ehliyet durumu, spor faaliyeti, önceden sözel TYD eğitimi alma durumu, önceden TYD maket eğitimi alma 
durumu, üniversitede sözel TYD eğitim alma durumu, üniversitede maket üzerinde TYD eğitimi alma durumu, kalp masajı eğitimi kaçıncı sınıfta verilmesi gerektiği, eğitim almadan önce kalp masajı yapabilirlilik durumu, maket üzerinde kompresyon yaparken bası yeri, bası derinliği, bası hızı, ritm ve eğitim sonrası kalp masajı yapabilirlilik verileri eğitim verildikten sonra maket üzerinde uygulama yaparken veri formlarına kaydedilerek, anket formundaki derecelendirme puanlarıyla karşılaştırıldı. Bası yeri, bası derinliği, bası hızı ve ritm puanlaması 5 puan üzerinden bir acil tıp uzmanı tarafından kaydedildi.

\section{İstatistiksel analiz}

Veriler SPSS 17.0 (Statistical Package for the Social Sciences, Chicago, IL, ABD) programına girildi. İstatistiksel analizde sürekli nonparametrik veriler için Mann Whitney $U$ testi, kesikli nonparametrik veriler için ise $\chi^{2}$ testi kullanılmıştır. $p<0,05$ değeri anlamlı olarak kabul edilmiştir.

\section{Bulgular}

Çalışmaya Pamukkale Üniversitesi İş Sağlığı ve Güvenliği bölümünde okuyan 254 öğrenci katılmıştır. Öğrencilerin 209'u (\%82,3) erkek, 45 'i $(\% 17,7)$ kadındı, 128 (\%50,4) öğrenci birinci öğretim, $126(\% 49,6)$ ikinci öğretim öğrencisi idi. Öğrencilerin 46'sı düz lise mezunu, 34'ü anadolu lisesi mezunu, 174'ü ise diğer tip lise mezunlarıydı. Ehliyeti olan öğrenci sayısı 110'du $(\% 43,3)$. Öğrencilerin 173'ü $(\% 68,1)$ bir spor dalı ile uğraşmakta, 46'sı $(\% 18,1)$ iki spor dalı ile uğraşmakta, 10 'u $(\% 3,9)$ üç ve daha fazla spor dalı ile uğraşmaktayken 25 'i $(\% 9,8)$ herhangi bir sporla uğraşmamaktaydı. Çalışmaya katılan öğrencilerin \%94,5'i KPR eğitiminin 1. sınıfta verilmesi gerektiğini belirtmişlerdir.

Üniversite öncesinde sözel olarak KPR eğitimi alan öğrencilerin sayısı $88(\% 34,6)$ iken, KPR eğitimi almamış olanların sayısı $166(\% 65,4)$ idi. Üniversite öncesinde maket üzerinde KPR eğitimi alan öğrenci sayısı 107 $(\% 42,1)$ iken, eğitim almayan öğrenci sayısı $147(\% 57,9)$ idi. Üniversitede sözel olarak KPR eğitimi almış olanların sayısı 235 (\%92,5) iken, eğitim almamış öğrencilerin sayısı $19(\% 7,5)$ idi. Üniversitede maket üzerinde KPR eğitimi almış olan öğrencilerin sayısı 242 (\%95,3) iken, eğitim almamış öğrencilerin sayısı $12(\% 4,7)$ idi. Üç öğrenci $(\% 1,2)$ ise üniversite öncesi ve üniversitede gerek sözel olarak gerekse maket üzerinde KPR eğitimi almadığını belirtmişlerdir.

Çalışmaya katılan öğrencilerin vücut kitle indeksi ortalaması 22,21 $\pm 3,24$ (ortalama \pm standart sapma) olarak saptandı. Çalışmaya katılan öğrencilerin bası yeri puan ortalaması 5 üzerinden $4,85 \pm 0,44$, bası derinliği puan ortalaması $4,77 \pm 0,53$, bası hızı puan ortalaması $4,69 \pm 0,59$, bası ritmi puan ortalaması $4,82 \pm 0,50$ olarak bulundu.

Çalışmada eğitim öncesi ve sonrasında sorulan "Şu an KPR yapar mısın?" sorusuna verilen cevaplardan yola çıkıldığında çalışma öncesinde "yapamam", "belki yaparım" diyen toplam $33(\% 13)$ kişi mevcutken çalışma sonrasında ise aynı soruya "yapamam", "belki yaparım" cevaplarını veren toplam 9 kişi $(\% 3,5)$ mevcut olup istatistiksel olarak çalışma öncesi ve sonrası kişilerin öz güvenlerinde anlamlı fark mevcuttur $(p=0,0001)$ (Tablo 1).

Üniversite öncesinde KPR konusunda sözel eğitim alan ve almayan öğrenciler arasında bası yeri $(p=0,850)$, bası derinliği $(p=0,953)$, bası hızı $(p=0,481)$ ve bası ritmi $(p=0,668)$ puanları açısından istatistiksel olarak anlamlı fark saptanmamıştır (Tablo 2).

Üniversite öncesinde KPR konusunda maket üzerinde eğitim alan öğrencilerde bası derinliği puanı maket eğitimi almamış öğrencilere göre daha yüksek saptanmıştır $(p=0,047)$ (Tablo 3).

Üniversitede sözel olarak KPR eğitimi alan öğrencilerin bası derinliği puanı sözel eğitim almamış öğrencilere göre yüksek saptanmıştır $(p=0,037)$ (Tablo 4).

Üniversitede maket üzerinde KPR eğitimi alan öğrencilerin bası yeri $(p=0,028)$, bası derinliği $(p=0,022)$, bası ritmi $(p=0,025)$ puanları maket üzerinde KPR eğitimi almamış öğrencilere göre yüksek saptanmıştır (Tablo 5). Grupların bası hızı puan ortalamaları ise $4,5^{\prime}$ in üstünde olup iyi düzeydedir.

Erkek ve kadın öğrencilerin bası yeri, bası derinliği, bası hızı ve bası ritmi puanlarına bakıldığında kadınlarda bası ritmi $(p=0,043)$ ve bası hızı $(p=0,033)$ puanlarının erkeklere göre istatistiksel olarak anlamlı yüksek olduğu saptanmıştır. Bası yeri $(p=0,352)$ ve bası derinliği $(p=0,414)$ puanları açısından erkek ve kız öğrenciler arasında fark saptanmamıştır. 
Tablo 1. Öğrencilerin eğitim öncesi ve sonrası özgüvenleri.

\begin{tabular}{lccc}
\hline & Yapamam-Belki & Yaparım-Kesinlikle Yaparım & $P$ \\
\hline & $\mathrm{n}(\%)$ & $\mathrm{n}(\%)$ & \\
Eğitim Öncesi & $33(13)$ & $221(87)$ & 0,0001 \\
Eğitim Sonrası & $9(3,5)$ & $245(96,5)$ & \\
\hline
\end{tabular}

p değeri $\chi^{2}$ testinden elde edilmiştir.

Tablo 2. Üniversite öncesi sözel eğitim alan ve almayan öğrencilerin göğüs basısı puanları.

\begin{tabular}{lccc}
\hline & \multicolumn{2}{c}{ Üniversite öncesi sözel eğitim } & \multirow{2}{*}{$p$} \\
\cline { 2 - 3 } & \multicolumn{1}{c}{ Almayan } & Alan & \\
\hline Bası Yeri & $4,84 \pm 0,471$ & $4,86 \pm 0,377$ & 0,850 \\
Bası Derinliği & $4,77 \pm 0,561$ & $4,78 \pm 0,490$ & 0,953 \\
Bası Hızı & $4,69 \pm 0,610$ & $4,67 \pm 0,562$ & 0,481 \\
Bası Ritm & $4,81 \pm 0,527$ & $4,84 \pm 0,452$ & 0,668 \\
\hline
\end{tabular}

$p$ değeri Mann Whitney $U$ testinden elde edilmiştir.

Tablo 3. Üniversite öncesi maket üzerinde eğitim alan ve almayan öğrencilerin göğüs basısı puanları.

\begin{tabular}{lccc}
\hline & \multicolumn{2}{c}{ Üniversite öncesi maket eğitim } & $p$ \\
\cline { 2 - 3 } & Almayan & Alan & \\
\hline Bası Yeri & $4,86 \pm 0,388$ & $4,83 \pm 0,504$ & 0,954 \\
Bası Derinliği & $4,72 \pm 0,571$ & $4,84 \pm 0,479$ & 0,047 \\
Bası Hızı & $4,66 \pm 0,614$ & $4,72 \pm 0,563$ & 0,489 \\
Bası Ritm & $4,84 \pm 0,478$ & $4,79 \pm 0,532$ & 0,244 \\
\hline
\end{tabular}

$p$ değeri Mann Whitney $U$ testinden elde edilmiştir.

Tablo 4. Üniversitede sözel eğitim alan ve almayan öğrencilerin göğüs basısı puanları.

\begin{tabular}{lccc}
\hline & \multicolumn{2}{c}{ Üniversite sonrası sözel eğitim } & $p$ \\
\cline { 2 - 3 } & \multicolumn{1}{c}{ Almayan } & Alan & \\
\hline Bası Yeri & $4.79 \pm 0.419$ & $4.85 \pm 0.442$ & 0.299 \\
Bası Derinliği & $4.68 \pm 0.603$ & $4.75 \pm 0.553$ & 0.037 \\
Bası Hızı & $4.74 \pm 0.452$ & $4.68 \pm 0.603$ & 0.964 \\
Bası Ritm & $4.84 \pm 0.375$ & $4.82 \pm 0.511$ & 0.849 \\
\hline
\end{tabular}

$p$ değeri Mann Whitney $U$ testinden elde edilmiştir.

Tablo 5. Üniversitede maket üzerinde eğitim alan ve almayan öğrencilerin göğüs basısı puanları

\begin{tabular}{lccc}
\hline & \multicolumn{2}{c}{ Üniversite sonrası maket eğitim } & \multirow{2}{*}{$p$ değeri } \\
\cline { 2 - 3 } & Almayan & Alan & \\
\hline Bası Yeri & $4,58 \pm 0,669$ & $4,86 \pm 0,423$ & 0,028 \\
Bası Derinliği & $4,42 \pm 0,793$ & $4,79 \pm 0,516$ & 0,022 \\
Bası Hızı & $4,42 \pm 0,900$ & $4,70 \pm 0,572$ & 0,317 \\
Bası Ritm & $4,33 \pm 1,073$ & $4,84 \pm 0,446$ & 0,025 \\
\hline
\end{tabular}

$p$ değeri Mann Whitney $\mathrm{U}$ testinden elde edilmiştir. 


\section{Tartışma}

TYD solunumu veya dolaşımı durmuş ve bilinci yerinde olmayan kişilere uygulanan; etkili yapıldığında mortalite ve morbiditeyi azaltan önemli bir uygulamadır. TYD uygulamalarının doğru bir şekilde yapılması ile geri döndürme oranlarında artışa sebep olmuştur. Bu uygulamalar TYD kılavuzları doğrultusunda kurtarıcılara aktarılmaktadır. AHA beş yılda bir bu kılavuzun güncellemesini yapmaktadır [5]. $\mathrm{Bu}$ kılavuzlardaki sadeleştirmelerle halktan kurtarıcıların daha fazla TYD uygulamalarına katılım göstermesi planlanmıştır. İsviçre'de yapılan bir çalışmada halkın \%19'u, Polonya'da ise \% 75 'inin TYD konusunda eğitildiği bildirilmiştir $[12,13]$. Yapılan taramalarda ülkemizde bu konuyla ilgili yeterli veri bulunamamıştır.

Çalışmaya katılan öğrencilerin çalışmamız sonunda özgüvenlerinde anlamlı bir artış olmuştur. Ayrıca sözel ve maket eğitimleri sonrasında bası yeri, bası derinliği ve ritm açısından anlamlı farklar olduğu saptanmıştır.

Çalışmaya katılan öğrencilerin \%94, ${ }^{\prime}$ i KPR eğitiminin 1. sınıfta verilmesi gerektiğini belirtmişlerdir. Başka bir çalışmada ise çalışmaya katılan öğrencilerin \%81'i $(n=218)$ TYD uygulamalarını bilmenin meslek hayatlarında kendilerine faydalı olacağını belirtmektedir [14]. Bizim çalışmamızda da öğrenciler benzer şekilde erken dönemde TYD eğitimi almak istemişlerdir.

Öğrencilere KPR eğitimi öncesinde sorulan "Şu anki bilgilerinle KPR yapabilir misin?" sorusuna 221 öğrenci $(\% 86,6)$ "yaparım" veya "kesinlikle yaparım" cevabını vermişlerdir. Aynı soru KPR eğitimi sonrası sorulduğunda ise "yaparım" veya "kesinlikle yaparım" cevabını veren öğrenci sayısı 245’ti $(\% 96,5)$. Bizim çalışmamıza benzer olarak yapılandırılan Özdinç ve ark.'nın [14] çalışmasında da 269 öğrencinin \%67,7'si (n=182) TYD ile ilgili eğitimi olsun olmasın gerektiğinde hiç çekinmeden TYD verebileceğini belirtmiştir. Aynı çalışmada TYD konusunda eğitim alan öğrencilerin \%67,1'i TYD'yi iyi bildiğini, \%64,7'si etkili TYD verebileceğini ve \%75,3'ü etkili kalp masajı yapabileceğini ifade etmiştir. Bizim çalışmamızda öğrencilerin eğitim sonrası özgüvenlerinin arttığı görülmüştür. Benzer şekilde yapılan farklı araştırmalarda da eğitimlerin özgüveni artırdığı görülmektedir [15-17].
Çalışmamızda KPR eğitimi sonrasında maket üzerindeki uygulamada öğrencilerin bası yeri, bası derinliği, hızı ve ritmi puanlandığında 5 üzerinden 4,5 ve üzeri olarak bulunmuştur. Castillo ve ark.'nın [18] araştırmasında kurs sonu teorik bilgilerinin benzer şekilde yüksek olduğu bulunmuştur. Bazı çalışmalarda ise yarıdan fazla teorik olarak başarılı cevap verme ve başarılı KPR yapabildikleri görülmüştür [14, 19].

Bir çalışmada ehliyet kurslarının ilk yardım bilgi düzeyine katkıda bulunduğu bildirilmiştir. Fakat çalışmamızda ehliyet sahibi olan ve olmayan öğrenciler arasında bası yeri, bası derinliği, bası hızı ve bası ritim puanları açııından istatistiksel anlamlı fark saptanmamıştır [20].

Çalışmamız üniversite öncesinde sözel eğitim almanın KPR uygulamalarına anlamlı katkı sağlamadığını göstermiş olup, maket üzerinde uygulama yapmanın ise sadece daha doğru bası derinliği uygulanmasını sağladığını göstermiştir. Üniversitede sözel olarak KPR eğitimi almak sadece bası derinliğinin daha doğru uygulamayı sağlamış iken maket üzerinde eğitim alındığında ise bası yeri, bası derinliği ve bası ritminin daha doğru uygulanmasını sağlamıştır. Noordergraaf ve ark.'nın [21] araştırmasında tekrarlanan eğitimlerin göğüs basılarının her basamağının güçlenmesini sağlayacağını göstermektedir. Sunulan araştırmada ise özellikle maket üzerinde verilen eğitimlerle göğüs basılarının birçok basamağının daha ideal hale geldiği ortaya çıkmıştır. Çalışmamız ayrıca kişilere eğitim verilecekse özellikle maket üzerinde uygulama yapılması gerektiğini ortaya koymuştur.

Çalışmamızda kadın öğrencilerde bası ritmi $(p=0,033)$ ve bası hızı $(p=0,043)$ puanlarının erkeklere göre istatistiksel olarak anlamlı yüksek olduğu saptanmıştır. Bası yeri ve bası derinliği açısından ise cinsiyetler arası fark olmadığı görülmüştür. Bazı araştırmalarda cinsiyet farklılığın TYD uygulamasında farklılığa yol açmadığı bulunmuştur [15, 22].

Çalışmamızın bazı kısıtıııklarıbulunmaktadır. Öğrenciler yalnızca göğüs basılarının özellikleri açısından değerlendirilmiştir. Maket üzerinde yapılan göğüs basılarının özellikleri sadece eğitim sonrasında kaydedilmiş olup, eğitim verilmeden öncesine dair veriler elde edilmemiştir. Ayrıca öğrencilerin daha önceden 
gerçek KPR tecrübelerinin olup olmadığına da bakılmamıştır.

Sonuç olarak yaşadıkları ve çalıştıkları bölgelerde çoğu zaman olay yerine sağlık profesyonellerinden daha hızlı ulaşabilecek olan iş sağlığı güvenliği öğrencilerine TYD eğitimleri öğrenim hayatlarının ilk yıllarından başlayarak özellikle maket üzerinde verilmeli, bilgi ve becerileri artırılması sağlanmalıdır.

Çıkar İlişkisi: Yazarlar çıkar ilişkisi olmadığını beyan eder.

\section{Kaynaklar}

1. Karataş M, Selçuk EB. History of the cardiopulmonary resuscitation. Kafkas J Med Sci 2012;2:84-87.

2. Grunfeld GB. Modern medicine and the emergence of biomedical ethics. Caduceus 1992;8:1-22.

3. Varon J, Sternbach GL. Cardiopulmonary resuscitation: Lessons from the past. J Emerg Med 1991;9:503-507.

4. Guidelines for the appropriate use of do not resuscitate orders. Council on ethical and judicial affairs, American Medical Association. JAMA 1991;265:1868-1871.

5. Türkiye Kardiyoloji Derneği, Kardiyopulmoner resüsitasyon ve acil kardiyak bakım bilimi için 2010 Amerikan Kalp Derneği (AHA) kılavuzu. http://www.tkdonline.org/PDFs/AHA-2012- kilavuzu.pdf. Erişim tarihi 27 Temmuz 2018.

6. Hollis $\mathrm{S}$, Gillespie N. An audit of basic life support skills amongst general practitioner principals: is there a need for regular training. Resuscitation 2000;44:171-175.

7. Wilcox-Gök VL. Survival from out of hospital cardiac arrest: A multivariate analysis. Med Care 1991;29:104114.

8. Hollenberg J, Bâng A, Lindqvist J, et al. Difference in survival after out-of-hospital cardiac arrest between the two largest cities in Sweden: a matter of time? J Intern Med 2005;257:247-254

9. Eckstein M, Stratton SJ, Chan LS. Cardiac arrest resuscitation evaluation in Los Angeles: CARE-LA. Ann Emerg Med 2005;45:504-509.

10. Sasson C, Rogers MA, Dahl J, Kellermann AL. Predictors of survival from out-of-hospital cardiac arrest: a systematic review and meta-analysis. Circ Cardiovasc Qual Outcomes 2010;3:63-81.

11. Kaan NM, Kurt İ, Gürsoy F. Üniversite hastanesinde temel yaşam desteği ve defibrilasyon kursu sonuçlarının değerlendirilmesi. ADÜ Tıp Fakültesi Derg 2010;11:1-7.

12. Axelsson A, Thorén A, Holmberg S, Herlitz J. Attitudes of trained Swedish lay rescuers toward CPR performance in an emergency. A survey of 1012 recently trained CPR rescuers. Resuscitation 2000;44:27-36.
13. Handley AJ, Bahr J, Baskett P, et al. The 1998 European Resuscitation Council guidelines for adult single rescuer basic life support: A statement from the Working Group on Basic Life Support, and approved by the executive committee. Resuscitation 1998;37:6780.

14. Özdinç Ş, Şensoy N, Aktaş R, Keskin G, Tunç D, Tüfek YE. Afyonkarahisar Polis Meslek Yüksekokulu öğrencilerinin temel yaşam desteği ile ilgili bilgi düzeylerinin saptanması. Kocatepe Tıp Derg 2014; 15:246-250.

15. Yılmaz A, Seyit $M$, Dal O, Bilge A, Hatipoğlu C. Ortaokul-lise ögrencilerine verilen temel yaşam desteği (TYD) eğitimlerinde iki yöntemin karşılaştırılması. Gaziosmanpaşa Üniversitesi Tıp Fakültesi Derg 2013;5:91-96.

16. Sopka S, Biermann H, Druener S, et al. Practical skills training influences knowledge and attitude of dental students towards emergency medical care. Eur J Dent Educ 2012;16:179-186.

17. Laurent F, Augustin P, Nabet C, Ackers S, Zamaroczy D, Maman L. Managing a cardiac arrest: Evaluation of final-year predoctoral dental students. J Dent Educ 2009; 73:211-217.

18. Castillo J, Gallart A, Rodríguez E, Castillo J, Gomar C. Basic life support and external defibrillation competences after instruction and at 6 months comparing face-to-face and blended training. Randomised trial. Nurse Educ Today 2018;65:232-238.

19. Bjorshol CA. Cardiopulmonary resuscitation skills. A survey among health and rescue personel outside hospital. Tidsskr Nor Laegeforen 1996;116:508-511.

20. Tomruk Ö, Soysal S, Karcıoğlu Ö. ve ark. DEÜTF acil servisine başvuran hastalara eşlik eden hasta yakınlarının ilk yardım bilgi düzeyleri ve etkileyen faktörler. The 1st World Congress of Emergency and Military Contingency Medicine; 2002:111.

21. Noordergraaf GJ, Be WK, Sabbe M, Reginald F, Diets RF, Noordergraaf A, Hemelrijck JW. Training needs and qualifications of anaesthesiologists not exposed to ALS. Resuscitation 1999;40:147-160.

22. Kara F, Yurdakul A, Erdoğan B, Polat E. The evaluation of updated basic life support Information of nurses working in a state hospital. MAKÜ Sag Bil Enst Derg 2015;3:17-26. 